\title{
Improving Competency in Emergency Airway Management through Multimodal Simulation-Based Training
}

\author{
Kastley Marvin ${ }^{1}$, Michael Coulter ${ }^{2}$, Mathew Marsee ${ }^{3}$, and Art Ambrosio ${ }^{1}$ \\ ${ }^{1}$ Naval Medical Center San Diego \\ ${ }^{2}$ Naval Medical Center San Dieg \\ ${ }^{3}$ Indiana University School of Medicine
}

November 3, 2020

\begin{abstract}
Introduction: Emergency airway management necessitates decisive action by all involved in the care of the patient, yet there is no standardized method for teaching these skills. The goal of this quality improvement project was to design and implement a simulation-based departmental training course aimed at otolaryngology-head and neck surgery residents and surgical technologists focusing on airway management. Methods: This was a single-center departmental quality improvement project. A one-day course in July 2019 consisted of five instructional stations including an adult airway management and fiberoptic intubation, endotracheal intubation and surgical airway management, pediatric airway management, rigid bronchoscopy, and emergency airway supplies. Participants completed a pre-test knowledge assessment and a survey of their comfort level as well as various timed procedures. After the course, participants completed another knowledge assessment and survey of comfort level. Results: A total of 18 participants completed the course. The average knowledge test scores improved significantly from $59.1 \%$ to $75.8 \%$ following training $(\mathrm{p}=0.02)$. The average levels for comfort with all aspects of airway management significantly increased after completing the course. The time to successful endotracheal intubation with video-assisted laryngoscopy improved from 88.3 seconds before the course to 29.7 seconds after instruction $(\mathrm{p}=0.001)$. Conclusion: Implementation of a departmental emergency airway management course is feasible and useful for both residents and novices, including surgical technologists, to be able to assist in these high-stakes situations.
\end{abstract}

\section{Hosted file}

Manusript - Department Airway Training - CO..DOCX available at https://authorea.com/users/ 372693/articles/490625-improving-competency-in-emergency-airway-management-throughmultimodal-simulation-based-training 
Figure 1: High-fidelity airway mannequins for intubation and cricothyroidotomy (Laerdal,

Wappingers Falls, New York)

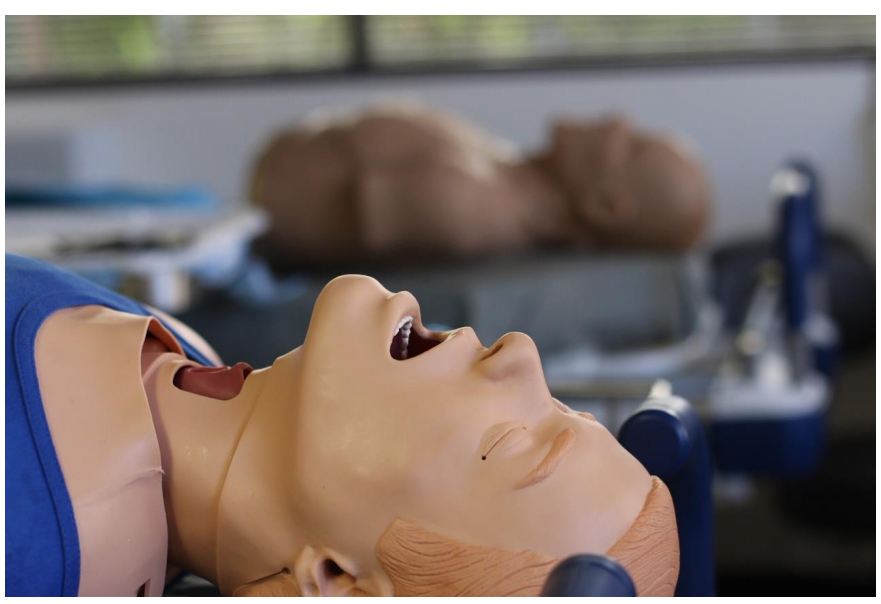


Figure 2: Transnasal awake flexible fiberoptic bronchoscopy and intubation simulation. Airway

mannequin, with Ambu aScope flexible bronchoscope and monitor (Ambu Inc., Columbia, MD).

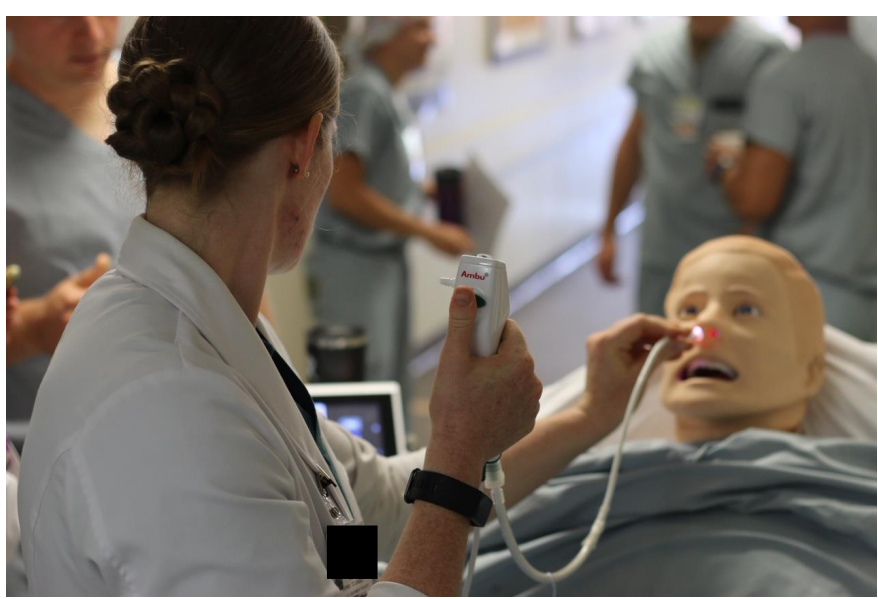


Figure 3: Pediatric ventilating ridgid bronchoscopy simulation

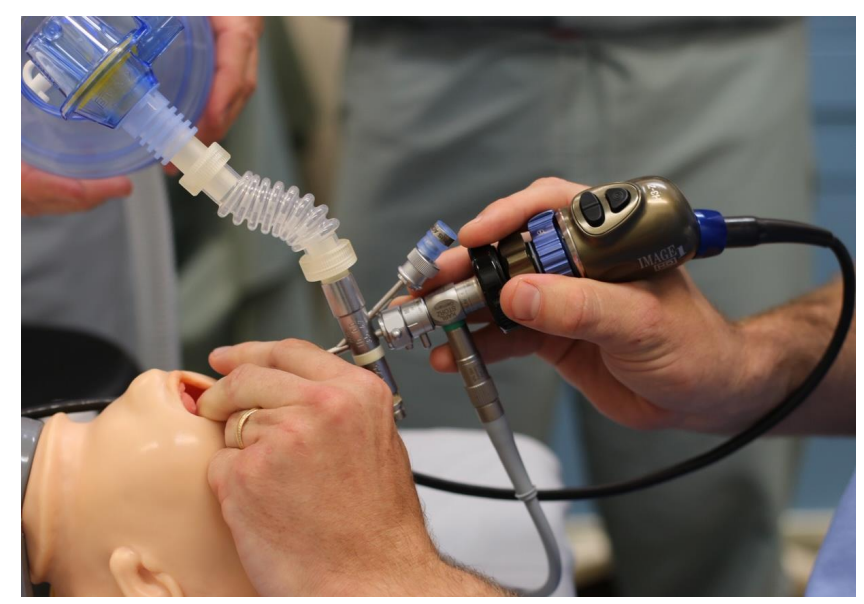

\section{Hosted file}

Figure 4.pdf available at https://authorea.com/users/372693/articles/490625-improvingcompetency-in-emergency-airway-management-through-multimodal-simulation-based-training 